Article

\title{
Ring-substituted 4-Hydroxy-1H-quinolin-2-ones: Preparation and Biological Activity
}

\section{Josef Jampilek ${ }^{1,2, *}$, Robert Musiol ${ }^{3}$, Matus Pesko ${ }^{4}$, Katarina Kralova ${ }^{4}$, Marcela Vejsova ${ }^{5}$, James Carroll $^{6}$, Aidan Coffey ${ }^{6}$, Jacek Finster ${ }^{3}$, Dominik Tabak ${ }^{3}$, Halina Niedbala ${ }^{3}$,} Violetta Kozik ${ }^{3}$, Jaroslaw Polanski ${ }^{3}$, Jozef Csollei ${ }^{2}$ and Jiri Dohnal ${ }^{1,2}$

1 Zentiva k.s., U kabelovny 130, 10237 Prague 10, Czech Republic

2 Department of Chemical Drugs, Faculty of Pharmacy, University of Veterinary and Pharmaceutical Sciences, Palackeho 1/3, 61242 Brno, Czech Republic

3 Institute of Chemistry, University of Silesia, Szkolna 9, 40007 Katowice, Poland; E-mail: robert.musiol@us.edu.pl (R.M.),polanski@us.edu.pl (J.P.)

4 Institute of Chemistry, Faculty of Natural Sciences, Comenius University, Mlynska dolina Ch-2, 84215 Bratislava, Slovakia; E-mail: kralova@fns.uniba.sk (M.P.)

5 Department of Biological and Medical Sciences, Faculty of Pharmacy in Hradec Kralove, Charles University in Prague, Heyrovskeho 1203, 50005 Hradec Kralove, Czech Republic; E-mail: marcela.vejsova@faf.cuni.cz (M.V.)

6 Department of Biological Sciences, Cork Institute of Technology, Bishopstown, Cork, Ireland; E-mail: james.carroll@cit.ie (J.C.), aidan.coffey@cit.ie (A.C.)

* Preliminary results were presented at The Twelfth Electronic Conference on Synthetic Organic Chemistry (ECSOC-12, http://www.usc.es/congresos/ecsoc/12/ECSOC12.htm), November 1-30, 2008 (paper C0012).

* Author to whom correspondence should be addressed; E-mail: josef.jampilek@zentiva.cz; Tel.: +42026724695; Fax: +420272701331.

Received: 4 February 2009; in revised form: 3 March 2009 / Accepted: 11 March 2009 / Published: 13 March 2009

Abstract: In the study, a series of twelve ring-substituted 4-hydroxy-1H-quinolin-2-one derivatives were prepared. The procedures for synthesis of the compounds are presented. The compounds were analyzed using RP-HPLC to determine lipophilicity and tested for their photosynthesis-inhibiting activity using spinach (Spinacia oleracea L.) chloroplasts. 
All the synthesized compounds were also evaluated for antifungal activity using in vitro screening with eight fungal strains. For all the compounds, the relationships between the lipophilicity and the chemical structure of the studied compounds are discussed, as well as their structure-activity relationships (SAR).

Keywords: Quinolinone derivatives; Lipophilicity; OER inhibition; Spinach chloroplasts; In vitro antifungal activity; Structure-activity relationships.

\section{Introduction}

The quinoline scaffold is present in many classes of biologically-active compounds [1]. A series of compounds derived from 8-hydroxyquinoline and styrylquinoline derivatives were recently synthesized as potential HIV-1 integrase inhibitors [2,3]. These compounds show a significant similarity to some novel antifungal agents, namely homoallylamines, and therefore possess potential antifungal activity [4]. Our previous study dealing with 8-hydroxyquinoline and styrylquinoline derivatives showed that they could also possess a strong antifungal activity [5-7]. According to the results reported recently, some new hydroxyquinoline derivatives also possess interesting herbicidal activities [6,8-13]. Some investigated compounds also showed antineoplastic activity [14].

Photosystem II (PS II) is a multisubunit membrane protein complex, which uses light energy to oxidize water and reduce plastoquinone. Binding of herbicides to photosystem II inhibits the electron transfer from $\mathrm{Q}_{\mathrm{A}}$ to $\mathrm{Q}_{\mathrm{B}}$ due to competition of herbicides with plastoquinone bound at the $\mathrm{Q}_{B}$ site. Thus, the $\mathrm{Q}_{\mathrm{B}}$ quinone-binding site of photosystem II is an important target for herbicides, including herbicides based on phenylurea moieties. It was found that a tail can be attached to the para position of phenylurea-type herbicides without any loss of binding, provided that the tail is hydrophobic. This indicates that the herbicides must be oriented in the $\mathrm{Q}_{\mathrm{B}}$ site so that these positions point toward the natural isoprenyl tail-binding pocket that extends out of the $\mathrm{Q}_{\mathrm{B}}$ site. In turn, the requirement that the tail must extend out of the $\mathrm{Q}_{\mathrm{B}}$ site constrains the size of the other herbicide substituents in the pocket [15]. In addition to phenylurea-type herbicides, various other compounds possessing an amide NHCO- moiety were also found to inhibit the photosynthetic electron transport [16-21]. Better understanding of these SAR relationships are not only important for the design of modern agricultural agents, but can also provide remarkable insights into the photosynthetic mechanisms of green cells.

Over the last three decades there has been a dramatic increase in the incidence of fungal infections, and the discovery of new drugs for the treatment of systemic mycoses is a major challenge in infectious disease research. There is an intensified need for new antifungal remedies with novel modes of action due to the rapid growth of the immunocompromised patient population, the development of resistance to the present azole therapies, and high toxicity of polyenes [22-24].

Compounds bearing a quinoline moiety are well known due to their broad biological activity [6]. In particular, hydroxyquinoline and its derivatives were introduced as antifungal agents in clinical practice and the novel compounds of this type are still investigated [25,26]. This paper deals with synthesis, herbicidal and antifungal activity of ring-substituted 4-hydroxy-1H-quinolin-2-one derivatives. All the compounds were tested for their photosynthesis-inhibiting activity (the inhibition 
of photosynthetic electron transport in spinach chloroplasts (Spinacia oleracea L.). Primary in vitro screening of all synthesized compounds was evaluated against eight fungal strains by means of the broth microdilution test in RPMI 1640 medium [27]. Lipophilicity ( $\log k$ ) of the compounds was determined using RP-HPLC. The procedure was performed under isocratic conditions with methanol as an organic modifier in the mobile phase using end-capped non-polar $\mathrm{C}_{18}$ stationary RP column. The structure-activity relationships of the compounds are also discussed.

\section{Results and Discussion}

\subsection{Chemistry}

In most of the synthesis protocols, aniline derivatives were used as the starting materials due to their convenient availability from chemical providers. Microwave assisted synthesis with malonic acid or its esters, was used to make compounds 1-4. Further nitration and reduction according to established procedures were used to make compounds 5 and $\mathbf{6}$. Acylation of $\mathbf{6}$ with cinnamoyl chloride provided compound 7. Diazo derivative $\mathbf{8}$ was made by means of a two-step synthesis from 4-aminobenzoic acid and diethyl malonate and gave 4-hydroxy-2-oxo-1,2-dihydroquinoline-6-carboxylic acid, which was coupled with the freshly prepared diazo salt derived from 4-nitro-2,5-dichloroaniline. Quinolines functionalized with carboxylic acid groups at $\mathrm{C}_{(3)}$ 9-12 were obtained in neat microwave assisted synthesis in moderate or good yield. Synthesis of all the above compounds is depicted in Scheme 1.

Scheme 1. General preparation of quinoline derivatives 1-12: (a) PPA, microwave irradiation; (b) $\mathrm{HNO}_{3}$; (c) $\mathrm{Sn}, \mathrm{HCl}$; (d) cinnamoyl chloride; (e) (2,5-dichloro-4nitrophenyl)diazonium chloride; (f) microwave irradiation; (g) hydrolysis.
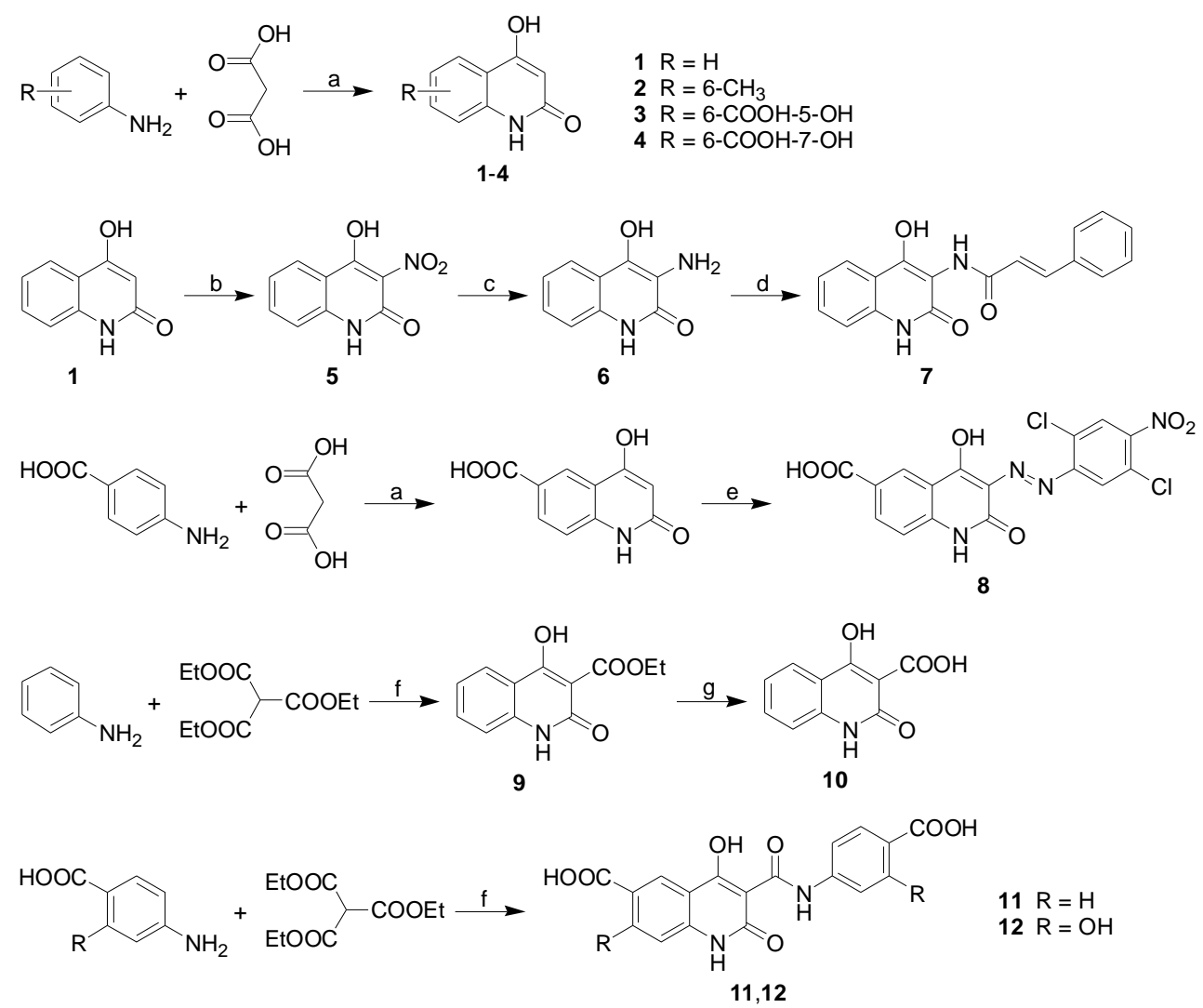


\subsection{Lipophilicity}

Hydrophobicities ( $\log P / C \log P$ values) of the compounds 1-12 were calculated using two commercially available programs and also measured by means of the reversed phase high performance liquid chromatography (RP-HPLC) method for lipophilicity measurement. The procedure was performed under isocratic conditions with methanol as an organic modifier in the mobile phase using an end-capped non-polar $\mathrm{C}_{18}$ stationary $\mathrm{RP}$ column. The capacity factors $k$ were determined and subsequent $\log k$ values were calculated.

The results are summarized in Table 1 and illustrated in Figure 1. The results obtained with all the compounds show that the experimentally-determined lipophilicities (log $k$ values) are lower than those indicated by the calculated $\log P / C \log P$, as shown in Figure 1, indicating relatively poor correlation between the experimentally-determined $\log k$ values and the calculated values. As expected, compound $\mathbf{8}$ showed the highest lipophilicity, while compound $\mathbf{3}$ possessed the lowest hydrophobicity, which was unexpected. Compound 7 showed less hydrophobicity contrary to all the results of the lipophilicity calculated by software. Comparing the lipophilicity data $\log k$ of both position analogues $\mathbf{3}$ and $\mathbf{4}$, it can be stated that the 7-hydroxy derivative $\mathbf{4}$ possessed higher hydrophobicity than 5-hydroxy analogue 3. The salicylic acid derivative $\mathbf{1 2}$ showed higher lipophilicity than benzoic derivative $\mathbf{1 1}$. These facts are caused by intramolecular interactions [28].

Figure 1. Comparison of the computed $\log P / C \log P$ values using the two programs with the calculated $\log k$ values. The discussed compounds 1-12 are ordered according to the $\log k$ values increase.

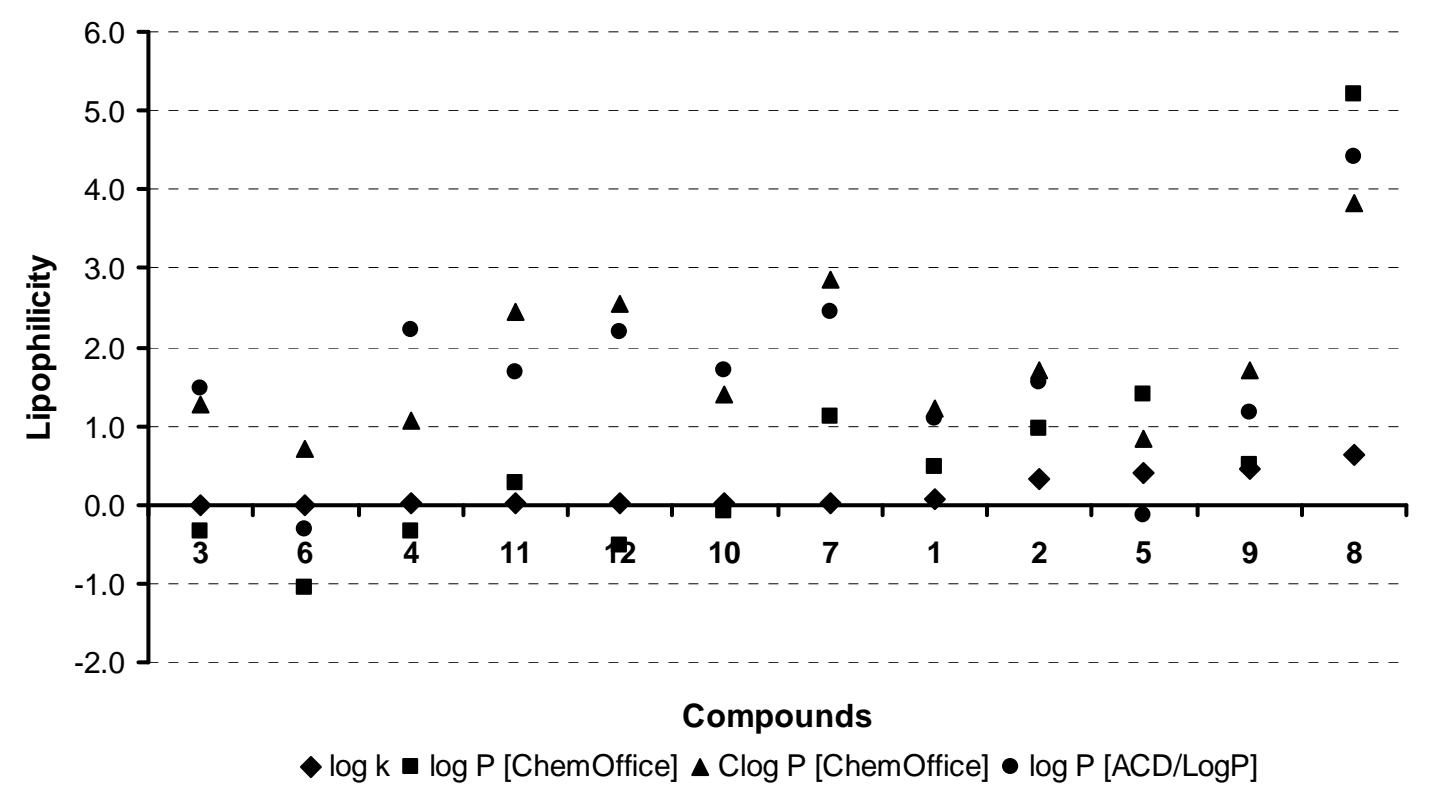


Table 1. Comparison of the calculated lipophilicities $(\log P / C \log P)$ with the determined $\log k$ values.

\begin{tabular}{|c|c|c|c|c|c|}
\hline & & $\mathrm{R}^{1}$ & $\int_{0}^{R^{2}}$ & & \\
\hline Comp. & $\mathbf{R}^{1}$ & $\mathbf{R}^{2}$ & $\log k$ & $\begin{array}{l}\log P / C \log P \\
\text { ChemOffice }\end{array}$ & $\begin{array}{c}\log P \\
\text { ACD/LogP }\end{array}$ \\
\hline 1 & $\mathrm{H}$ & $\mathrm{H}$ & 0.0664 & $0.49 / 1.216$ & $1.10 \pm 0.75$ \\
\hline 2 & $6-\mathrm{CH}_{3}$ & $\mathrm{H}$ & 0.3307 & $0.97 / 1.715$ & $1.56 \pm 0.75$ \\
\hline 3 & 6-COOH-5-OH & $\mathrm{H}$ & 0.0002 & $-0.34 / 1.261$ & $1.47 \pm 0.75$ \\
\hline 4 & 6-COOH-7-OH & $\mathrm{H}$ & 0.0080 & $-0.34 / 1.070$ & $2.22 \pm 0.75$ \\
\hline 5 & $\mathrm{H}$ & $-\mathrm{NO}_{2}$ & 0.4052 & 1.39 / 0.836 & $-0.14 \pm 1.00$ \\
\hline 6 & $\mathrm{H}$ & $-\mathrm{NH}_{2}$ & 0.0004 & $-1.06 / 0.719$ & $-0.32 \pm 1.00$ \\
\hline 7 & $\mathrm{H}$ & & 0.0128 & $1.11 / 2.848$ & $2.45 \pm 1.00$ \\
\hline 8 & 6-COOH & & 0.6394 & $5.22 / 3.840$ & $4.41 \pm 1.00$ \\
\hline 9 & $\mathrm{H}$ & $-\mathrm{COOC}_{2} \mathrm{H}_{5}$ & 0.4595 & $0.51 / 1.694$ & $1.17 \pm 0.75$ \\
\hline 10 & $\mathrm{H}$ & $-{ }_{\mathrm{CoOH}}^{\mathrm{COOH}}$ & 0.0118 & $-0.09 / 1.409$ & $1.71 \pm 0.35$ \\
\hline 11 & 6-COOH & & 0.0081 & $0.27 / 2.445$ & $1.67 \pm 1.00$ \\
\hline 12 & 6-COOH-5-OH & & 0.0093 & $-0.51 / 2.543$ & $2.20 \pm 1.00$ \\
\hline
\end{tabular}

\subsection{Oxygen evolution rate inhibition in spinach chloroplasts}

All compounds were evaluated for their in vitro herbicidal efficiency. The results are listed in Table 2. Quinoline derivatives 1-12 showed a wide range of activity related to inhibition of oxygen evolution rate (OER) in spinach chloroplasts. Two compounds showed interesting $\mathrm{IC}_{50}$ (half maximal inhibitory concentration) values: $126 \mu \mathrm{mol} / \mathrm{L}(\mathbf{8})$ and $157 \mu \mathrm{mol} / \mathrm{L}(2)$; nevertheless the studied activity of all the other compounds was very low.

Due to the moderate and/or low activity of compounds 1-12, it is difficult to determine simple structure-activity relationships. However some interesting observations can be made: in the case of compound 1, an unsubstituted structure did not have any effect on OER in chloroplasts. The remaining compounds could be divided into two groups according to their chemical structure. Group 1 includes compounds 2-4, 8, 11 and 12, and Group 2 compounds 5-7, 9 and 10.

Group 1 showed higher biological activity than Group 2. The activity related to OER inhibition seems to be positively influenced by substitution of ring $\mathrm{B}$ : especially the $\mathrm{C}_{(6)}$ position (see compounds $\mathbf{2 - 4}, \mathbf{1 1}, \mathbf{1 2}$ ). Comparison of the OER-inhibiting activities of compounds 2-4, 8, 11 and 12 also indicated that the lipophilicity increase is connected with the quasi-parabolic increase of biological activity (Figure 2). 
Table 2. $\mathrm{IC}_{50}$ values related to OER inhibition in spinach chloroplasts in comparison with 3-(3,4-dichlorophenyl)-1,1-dimethylurea (DCMU) standard and in vitro antifungal activity $\left(\mathrm{IC}_{80}\right)$ of compounds 1-12 compared with fluconazole (FLU) standard.

\begin{tabular}{|c|c|c|c|c|c|c|c|c|c|}
\hline \multirow{4}{*}{ Comp. } & \multirow{4}{*}{$\begin{array}{c}\text { OER } \\
\text { inhibition } \\
\text { IC }_{50} \\
{[\mu \mathrm{mol} / \mathrm{L}]}\end{array}$} & \multicolumn{8}{|c|}{$\mathrm{MIC} / \mathrm{IC}_{80}[\mu \mathrm{mol} / \mathrm{L}]$} \\
\hline & & $\mathbf{C A}$ & CT & CK & CG & TB & $\mathbf{A F}$ & $\mathbf{A C}$ & $\mathbf{T M}$ \\
\hline & & $24 h$ & $24 h$ & $24 h$ & $24 h$ & $24 h$ & $24 h$ & $24 h$ & $72 h$ \\
\hline & & $48 h$ & $48 \mathrm{~h}$ & $48 h$ & $48 h$ & $48 h$ & $48 h$ & $48 h$ & $120 h$ \\
\hline \multirow{2}{*}{1} & \multirow{2}{*}{925} & $>500$ & $>500$ & $>500$ & $>500$ & $>500$ & $>500$ & $>500$ & $>500$ \\
\hline & & $>500$ & $>500$ & $>500$ & $>500$ & $>500$ & $>500$ & $>500$ & $>500$ \\
\hline \multirow{2}{*}{2} & \multirow{2}{*}{157} & $>500$ & $>500$ & $>500$ & $>500$ & $>500$ & $>500$ & $>500$ & $>500$ \\
\hline & & $>500$ & $>500$ & $>500$ & $>500$ & $>500$ & $>500$ & $>500$ & $>500$ \\
\hline \multirow{2}{*}{3} & \multirow{2}{*}{346} & 125 & 500 & $>500$ & 250 & 250 & $>500$ & $>500$ & $>500$ \\
\hline & & 125 & $>500$ & $>500$ & 250 & $>500$ & $>500$ & $>500$ & $>500$ \\
\hline \multirow{2}{*}{4} & \multirow{2}{*}{538} & 15.62 & 500 & $>500$ & 62.50 & 62.50 & 500 & $>500$ & $>500$ \\
\hline & & 62.50 & $>500$ & $>500$ & 250 & $>500$ & $>500$ & $>500$ & $>500$ \\
\hline \multirow{2}{*}{5} & \multirow{2}{*}{510} & $>500$ & $>500$ & $>500$ & $>500$ & $>500$ & $>500$ & $>500$ & $>500$ \\
\hline & & $>500$ & $>500$ & $>500$ & $>500$ & $>500$ & $>500$ & $>500$ & $>500$ \\
\hline \multirow{2}{*}{6} & \multirow{2}{*}{775} & $>500$ & $>500$ & $>500$ & $>500$ & $>500$ & $>500$ & $>500$ & $>500$ \\
\hline & & $>500$ & $>500$ & $>500$ & $>500$ & $>500$ & $>500$ & $>500$ & $>500$ \\
\hline \multirow{2}{*}{7} & \multirow{2}{*}{916} & $>125$ & $>125$ & $>125$ & $>125$ & $>125$ & $>125$ & $>125$ & $>125$ \\
\hline & & $>125$ & $>125$ & $>125$ & $>125$ & $>125$ & $>125$ & $>125$ & $>125$ \\
\hline \multirow{2}{*}{8} & \multirow{2}{*}{126} & 31.25 & 250 & 250 & 250 & 250 & 125 & 62.50 & 62.50 \\
\hline & & 125 & $>250$ & 250 & $>250$ & $>250$ & 250 & 250 & 125 \\
\hline \multirow{2}{*}{9} & \multirow{2}{*}{494} & $>500$ & $>500$ & $>500$ & $>500$ & $>500$ & $>500$ & $>500$ & $>500$ \\
\hline & & $>500$ & $>500$ & $>500$ & $>500$ & $>500$ & $>500$ & $>500$ & $>500$ \\
\hline \multirow{2}{*}{10} & \multirow{2}{*}{567} & $>500$ & $>500$ & $>500$ & $>500$ & $>500$ & $>500$ & $>500$ & $>500$ \\
\hline & & $>500$ & $>500$ & $>500$ & $>500$ & $>500$ & $>500$ & $>500$ & $>500$ \\
\hline \multirow{2}{*}{11} & \multirow{2}{*}{380} & $>500$ & $>500$ & $>500$ & $>500$ & $>500$ & $>500$ & $>500$ & $>500$ \\
\hline & & $>500$ & $>500$ & $>500$ & $>500$ & $>500$ & $>500$ & $>500$ & $>500$ \\
\hline \multirow{2}{*}{12} & \multirow{2}{*}{321} & 62.50 & 500 & $>500$ & 125 & 125 & 500 & 500 & 500 \\
\hline & & 125 & $>500$ & $>500$ & 250 & $>500$ & $>500$ & $>500$ & $>500$ \\
\hline DCMU & 1.9 & - & - & - & - & - & - & - & - \\
\hline \multirow{2}{*}{ FLU } & & 0.06 & 0.12 & 3.91 & 0.98 & 0.24 & $>125$ & $>125$ & 1.95 \\
\hline & & 0.12 & $>125$ & 15.62 & 3.91 & 0.48 & $>125$ & $>125$ & 3.91 \\
\hline
\end{tabular}

It is noteworthy that there are great differences in OER inhibition levels caused by positional isomers 3 (6-COOH-5-OH) and 4 (6-COOH-7-OH). Introducing a further phenolic moiety in compound 12 (salicylic derivative) positively influenced OER inhibition. The higher inhibitory effect of compound 8 compared with compound $\mathbf{2}$ may have resulted from higher lipophilicity (easier penetration of the compound through cell walls) and/or redox properties of the nitro moiety of the 2,5-dichloro-4-nitrophenyldiazenyl substituent. 
Figure 2. Relationships between the OER inhibition $\log \left(1 / \mathrm{IC}_{50}\right)[\mathrm{mmol} / \mathrm{L}]$ in spinach chloroplasts and lipophilicity (log $k$ ) of the studied compounds 1-12.

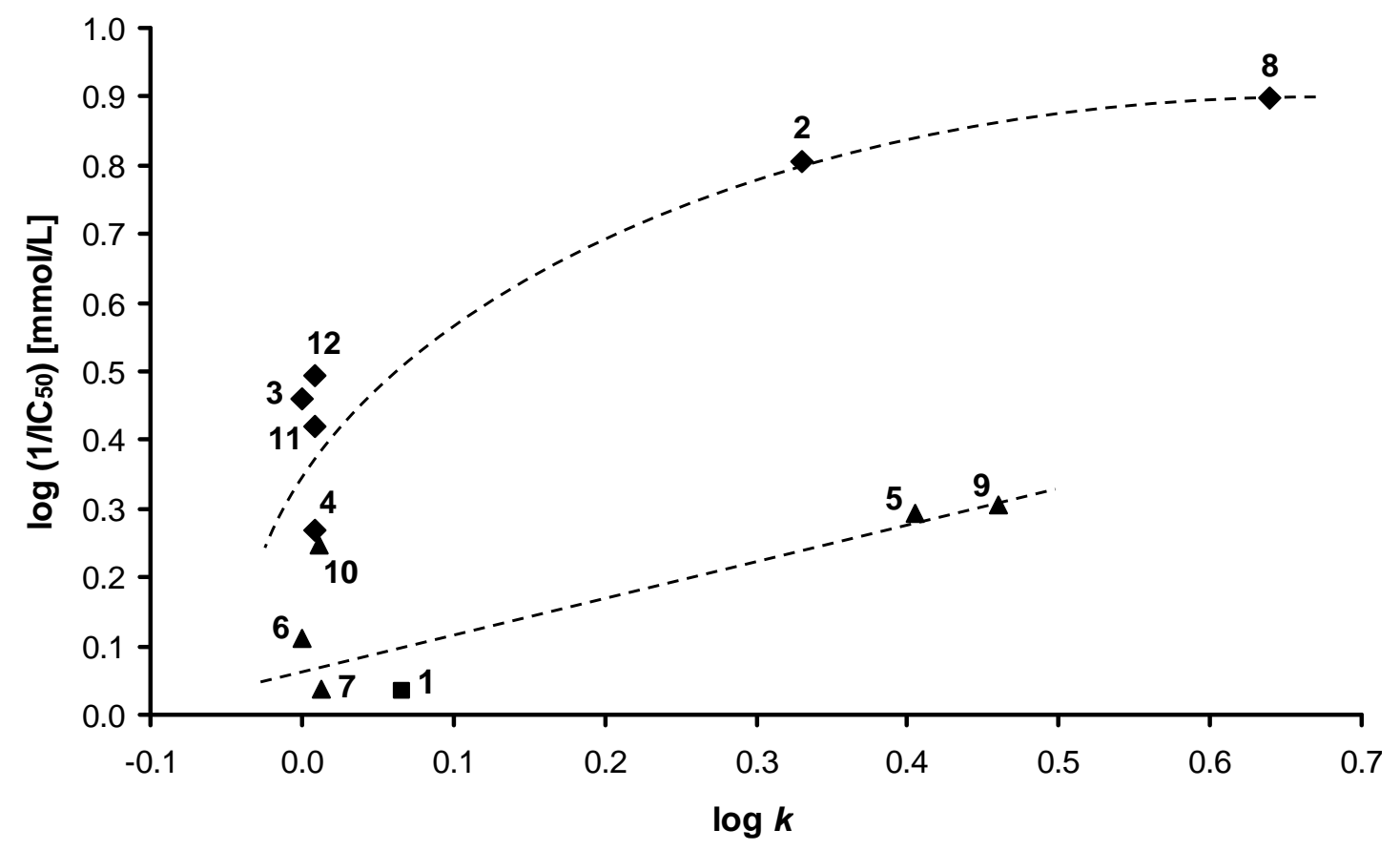

Generally, Group 2 compounds only caused slight inhibition of OER; nevertheless compounds 5 and 9 were approximately twice as effective as compound 1. All these compounds possess the substituted position $\mathrm{C}_{(3)}$ of ring $\mathrm{A}$, which caused the decrease in OER inhibition compared with Group 1 compounds. The most active compound from Group 2 was the ester 9.

\subsection{In vitro antifungal susceptibility testing}

All the compounds were tested for their in vitro antifungal activity. Compounds 1-3, 5-7, 9-11 did not show any activity and compounds 4,8 and 12 showed only a moderate activity, especially against Candida albicans ATCC 44859. Compound 4 showed medium activity against Candida glabrata 20/I, and compound $\mathbf{8}$ against Trichophyton mentagrophytes 445. The activities of the compounds are shown in Table 2.

Generally, it can be stated that in vitro antifungal activity depends on heteroaromatic ring A. Hydrogenation of ring $\mathrm{A}$ and introduction of keto group resulted in the loss of the antifungal effect compared with hydroxyquinoline derivatives [6,7]. Substitution of the $\mathrm{C}_{(3)}$ position by various moieties did not have a significant influence on the activity. Nevertheless salicylic acid derivative $\mathbf{1 2}$ showed a higher activity compared with benzoic derivative $\mathbf{1 1}$, probably due to the substitution of the $\mathrm{C}_{(3)}$ ' position by phenolic moiety.

Unsubstituted ring $\mathrm{B}$ or $\mathrm{C}_{(6)}$ substitution by a methyl moiety did not results in any activity. Substitution of phenyl ring $\mathrm{B}$ by 6-COOH (compounds 3, 4, 8 and 11, 12) caused the activity to increase. Position of the phenolic moiety seems to be a very important parameter for antifungal activity. While a 6-COOH-5-OH substitution pattern (compound 3 ) did not show any activity increase, introduction of 6-COOH along with a 7-OH moiety (compound 4) increased the activity significantly. The antifungal activity of compounds $\mathbf{8}$ and 12 was connected with 2,4-dichloro-4-nitrophenyldiazenyl 
and 3-(4-carboxy-3-hydroxyphenylcarbamoyl) substituents, respectively. According to the results, it can be assumed that lipophilicity is only of secondary importance for antifungal activity.

\section{Conclusions}

A series of twelve ring-substituted 4-hydroxy-1H-quinolin-2-one derivatives were prepared and characterized. All the prepared quinoline derivatives were analyzed using a RP-HPLC method for the lipophilicity measurement and their lipophilicity was determined. The prepared compounds were tested for their photosynthesis-inhibiting activity (the inhibition of photosynthetic electron transport in spinach chloroplasts (Spinacia oleracea L.) and for their antifungal activity. (E)-3-[(2,5-Dichloro-4nitrophenyl)diazenyl]-4-hydroxy-2-oxo-1,2-dihydroquinoline-6-carboxylic acid (8) showed the highest OER inhibition activity and 4,7-dihydroxy-2-oxo-1,2-dihydroquinoline-6-carboxylic acid (4) and compound $\mathbf{8}$ possessed the highest in vitro antifungal activity within the series.

\section{Experimental}

\subsection{General}

All reagents were purchased from Aldrich. Kieselgel 60, 0.040-0.063 mm (Merck, Darmstadt, Germany) was used for column chromatography. TLC experiments were performed on alumina-backed silica gel 40 F254 plates (Merck, Darmstadt, Germany). The plates were illuminated under UV (254 nm) and evaluated in iodine vapour. The melting points were determined on Boetius PHMK 05 (VEB Kombinat Nagema, Radebeul, Germany) and are uncorrected. Elemental analyses were carried out on an automatic Perkin-Elmer 240 microanalyser (Boston, USA). The purity of the final compounds was checked by the HPLC separation module Waters Alliance 2695 XE (Waters Corp., Milford, MA, U.S.A.). The detection wavelength $210 \mathrm{~nm}$ was chosen. The peaks in the chromatogram of the solvent (blank) were deducted from the peaks in the chromatogram of the sample solution. The purity of individual compounds was determined from the area peaks in the chromatogram of the sample solution. UV spectra $(\lambda, \mathrm{nm})$ were determined on a Waters Photodiode Array Detector 2996 (Waters Corp., Milford, MA, U.S.A.) in ca $6 \times 10^{-4}$ mol methanolic solution and $\log \varepsilon$ (the logarithm of molar absorption coefficient $\varepsilon$ ) was calculated for the absolute maximum $\lambda_{\max }$ of individual target compounds. Infrared spectra were recorded in a Smart MIRacle ${ }^{\mathrm{TM}}$ ATR ZnSe for Nicolet ${ }^{\mathrm{TM}} 6700$ FT-IR Spectrometer (Thermo Scientific, U.S.A.). Spectra are corrigated. All ${ }^{1} \mathrm{H}$ NMR spectra were recorded on a Bruker AM-500 (499.95 MHz for $\left.{ }^{1} \mathrm{H}\right)$, Bruker BioSpin Corp.,

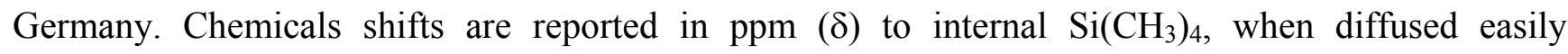
exchangeable signals are omitted.

4-Hydroxyquinolin-2(1H)-one (1). Preparation of PPA: $\mathrm{P}_{2} \mathrm{O}_{5}(287.9 \mathrm{~g})$ was added to $85 \%$ phosphoric acid $(200 \mathrm{~g}, 118.4 \mathrm{~mL})$ under stirring and microwave heating. The mixture was then heated for $15 \mathrm{~min}$. Aniline $(7 \mathrm{~mL}, 5 \mathrm{mmol})$ and malonic acid $(5.2 \mathrm{~g}, 5 \mathrm{mmol})$ were thoroughly mixed with $20 \mathrm{~g}$ PPA and heated under stirring in microwave reactor at $400 \mathrm{~W}$ during $2 \times 20 \mathrm{~min}$ with $5 \mathrm{~min}$ interval. The temperature reached $210{ }^{\circ} \mathrm{C}$. Then the mixture was poured into crushed ice and the beige solid was filtered and purified by extraction with EtOH and a white crystalline compound was obtained [29]. 
Yield 35\%; Mp $340{ }^{\circ} \mathrm{C}$; HPLC purity 97.12\%; UV (nm), $\lambda_{\max } / \log \varepsilon: 231.3 / 3.51 ; \mathrm{IR}\left(\mathrm{cm}^{-1}\right): 3618,1180$ $(\mathrm{OH}), 3043$ (=CH-), 1670 (lactam), $1650(\mathrm{C}=\mathrm{O}), 1593(\mathrm{Ph}), 1522(\mathrm{NH})$.

4-Hydroxy-6-methylquinolin-2(1H)-one (2). The product was obtained according to the previously described procedure [30,31] as a light brown crystalline compound. Yield 35\%; Mp $320{ }^{\circ} \mathrm{C}$; HPLC purity 97.72\%; UV (nm), $\lambda_{\max } / \log \varepsilon: 232.4 / 3.55$; IR ( $\left.\mathrm{cm}^{-1}\right): 3618,1180(\mathrm{OH}), 3044$ (=CH-), 2965, 1379 $\left(\mathrm{CH}_{3}\right), 1668$ (lactam), $1652(\mathrm{C}=\mathrm{O}), 1592(\mathrm{Ph}), 1522(\mathrm{NH})$.

4,5-Dihydroxy-2-oxo-1,2-dihydroquinoline-6-carboxylic acid (3). Naphthalene (15.4 g, $0.12 \mathrm{~mol})$ and malonic acid $(18.7 \mathrm{~g}, 0.18 \mathrm{~mol})$ were melted with stirring under temperature control $\left(<150{ }^{\circ} \mathrm{C}\right)$ to avoid decarboxylation of the acid. $\mathrm{POCl}_{3}(32.9 \mathrm{~g}, 0.36 \mathrm{~mol})$ was then added dropwise over $30 \mathrm{~min}$ and p-aminosalicylic acid $(15.3 \mathrm{~g}, 0.1 \mathrm{~mol})$ was then added. The resulting mixture was heated for $30 \mathrm{~min}$ and allowed to cool. Water $(100 \mathrm{~mL})$ was added to the warm mixture and the solution was made alkaline to $\mathrm{pH} 9$ with $20 \% \mathrm{NaOH}$. After cooling on ice precipitated naphthalene, it was filtered and the filtrate was acidified to $\mathrm{pH}$ 2. The product was filtered again and crystallized from acetic acid as a bright yellow crystalline compound. Yield $36 \%$; Mp $250{ }^{\circ} \mathrm{C}$; Anal. calc. for $\mathrm{C}_{10} \mathrm{H}_{7} \mathrm{NO}_{5}$ (221.16): C $54.31 \%$, H 3.19\%; found: C 54.51\%, H 4.11\%; HPLC purity 98.74\%; UV (nm), $\lambda_{\max } / \log \varepsilon: 244.2 / 3.54$; IR ( $\left.\mathrm{cm}^{-1}\right)$ : 3620, $1180(\mathrm{OH}), 3045$ (=CH-), 2950, 1690 (acid), 1672 (lactam), $1650(\mathrm{C}=\mathrm{O}), 1598(\mathrm{Ph})$, $1523(\mathrm{NH}), 1329,1198\left(\mathrm{OH}_{\text {phenol }}\right) ;{ }^{1} \mathrm{H}-\mathrm{NMR}\left(\mathrm{DMSO}_{6}\right)$ d: $5.65(\mathrm{~s}, 1 \mathrm{H}), 6.60(\mathrm{~d}, J=8.3 \mathrm{~Hz}, 1 \mathrm{H}), 7.80$ (d, J=8.3 Hz, 1H), 11.3 (bs, 1H), 12.20 (bs, 1H).

4,7-Dihydroxy-2-oxo-1,2-dihydroquinoline-6-carboxylic acid (4). The product was obtained as an isomer of 3 during its synthesis. Isolated by fractional crystalization as a white crystalline compound. Yield 36\%; Mp $250{ }^{\circ} \mathrm{C}$; Anal. calc. for $\mathrm{C}_{10} \mathrm{H}_{7} \mathrm{NO}_{5}$ (221.16): C 54.31\%, H 3.19\%; found: C 54.09\%, $\mathrm{H}$ $3.52 \%$; HPLC purity 98.51\%; UV (nm), $\lambda_{\max } / \log \varepsilon: 243.0 / 3.54 ; \mathrm{IR}\left(\mathrm{cm}^{-1}\right): 3618,1181(\mathrm{OH}), 3043$ (=CH-), 2948, 1693 (acid), 1670 (lactam), $1651(\mathrm{C}=\mathrm{O}), 1599(\mathrm{Ph}), 1521(\mathrm{NH}), 1328,1200\left(\mathrm{OH}_{\text {phenol }}\right)$; ${ }^{1} \mathrm{H}-\mathrm{NMR}\left(\mathrm{DMSO}-\mathrm{d}_{6}\right) \delta: 5.60(\mathrm{~s}, 1 \mathrm{H}), 6.67(\mathrm{~s}, 1 \mathrm{H}), 8.25(\mathrm{~s}, 1 \mathrm{H})$.

4-Hydroxy-3-nitroquinolin-2(1H)-one (5). The product was obtained according to the described nitration procedure [32] as a yellow crystalline compound. Yield 71\%; Mp 252-255 ${ }^{\circ} \mathrm{C}$; HPLC purity 99.72\%; UV (nm), $\lambda_{\max } / \log \varepsilon: 336.8 / 3.57$; IR $\left(\mathrm{cm}^{-1}\right)$ : 3620, $1181(\mathrm{OH}), 1712(\mathrm{C}=\mathrm{O}), 1682$ (lactam), $1622\left(\mathrm{C}=\mathrm{C}_{\text {cycle }}\right), 1595(\mathrm{Ph}), 1547\left(\mathrm{NO}_{2}\right), 1525(\mathrm{NH})$.

3-Amino-4-hydroxyquinolin-2(1H)-one (6). Compound $6(2.0 \mathrm{~g}, 0.0097 \mathrm{~mol})$ and tin powder $(3.8 \mathrm{~g}, 0.032 \mathrm{~mol})$ were stirred with $36 \% \mathrm{HCl}(8.1 \mathrm{~mL})$. The mixture was warmed at $80-90{ }^{\circ} \mathrm{C}$ for $30 \mathrm{~min}$. The brown solution was cooled to room temperature and filtered. The filtrate was alkalized with $\mathrm{NH}_{3(\mathrm{aq})}$ and warmed for $20 \mathrm{~min}$. Then Celite $(1.3 \mathrm{~g})$ was added and filtered. The solid was washed thoroughly with hot water $\left(80^{\circ} \mathrm{C}\right)$. The combined filtrates were concentrated and acidified. After cooling a white crystalline compound was obtained. Yield $85 \%$; Mp $300{ }^{\circ} \mathrm{C}$ [33]; HPLC purity 91.99\%; UV (nm), $\lambda_{\max } / \log \varepsilon: 232.8 / 3.53 ; \mathrm{IR}\left(\mathrm{cm}^{-1}\right): 3620,1181(\mathrm{OH}), 3312,1618\left(\mathrm{NH}_{2}\right), 1670$ (lactam), $1650(\mathrm{C}=\mathrm{O}), 1625\left(\mathrm{C}=\mathrm{C}_{\text {cycle }}\right), 1598(\mathrm{Ph}), 1523(\mathrm{NH})$. 
(2E)- $\mathrm{N}$-(4-Hydroxy-2-oxo-1,2-dihydroquinolin-3-yl)-3-phenylprop-2-enamide (7). Compound 7 (0.018 $\mathrm{g}, 0.001 \mathrm{~mol})$ was mixed with water $(5 \mathrm{~mL}), \mathrm{Et}_{2} \mathrm{O}(5 \mathrm{~mL})$ and sodium bicarbonate $(0.3 \mathrm{~g})$. The resulted mixture was stirred in an ice bath $\left(-3^{\circ} \mathrm{C}\right)$ and $10 \mathrm{~mL}$ of $\mathrm{Et}_{2} \mathrm{O}$ solution of cinamoyl chloride $(0.017 \mathrm{~g}$, $0.001 \mathrm{~mol})$ was added slowly. The resulting mixture was stirred at room temperature for 2 days, cooled in fridge and filtered. $\mathrm{Et}_{2} \mathrm{O}$ was added to the solid and dried. A white crystalline compound was obtained. Yield 50\%; Mp $145{ }^{\circ} \mathrm{C}$; Anal. calc. for $\mathrm{C}_{18} \mathrm{H}_{14} \mathrm{~N}_{2} \mathrm{O}_{3}+\mathrm{H}_{2} \mathrm{O}$ (324.33): C $66.66 \%$, H 4.97\%; found: C 66.54\%, H 5.27\%; HPLC purity 99.79\%; UV (nm), $\lambda_{\max } / \log \varepsilon: 263.1 / 3.51$; IR $\left(\mathrm{cm}^{-1}\right): 3620,1180(\mathrm{OH}), 3035\left(\mathrm{CH}_{\text {arom }}\right), 1670$ (lactam), $1650(\mathrm{C}=\mathrm{O}), 1648$ (amide), 1628 $\left(\mathrm{C}=\mathrm{C}_{\text {cycle }}\right), 1618,974(\mathrm{C}=\mathrm{C}), 1599(\mathrm{Ph}), 1525(\mathrm{NH})$; ${ }^{1} \mathrm{H}-\mathrm{NMR}\left(\mathrm{DMSO}-d_{6}\right) \delta: 3.30(\mathrm{~s}, 1 \mathrm{H}), 6.50(\mathrm{~d}$, $J=16.2 \mathrm{~Hz}, 2 \mathrm{H}), 7.10$ (s, 1H), $7.38(\mathrm{~m}, 9 \mathrm{H}), 7.5$ (s, 1H).

(E)-3-[(2,5-Dichloro-4-nitrophenyl)diazenyl]-4-hydroxy-2-oxo-1,2-dihydroquinoline-6-carboxylic acid (8). 4-Hydroxy-2-oxo-1,2-dihydroquinoline-6-carboxylic acid was obtained as compound 3 from 4-aminobenzoic acid and used without thorough purification in further synthesis as follows. IR $\left(\mathrm{cm}^{-1}\right)$ : 3618, 1179 (OH), 3043 (=CH-), 2948, 1686 (acid), 1677 (lactam), 1650 (C=O), 1599 (Ph), 1523 (NH); ${ }^{1} \mathrm{H}-\mathrm{NMR}\left(\mathrm{DMSO}-d_{6}\right)$ ) 7.7 (s, 1H), 7.9 (m, 3H), 10.43 (s, 1H), 10.47 (s, 1H), 12.7 (s, 1H). 2,5Dichloro-4-nitroaniline (0.92 g) was dissolved in $2: 1 \mathrm{Et}_{2} \mathrm{O} / \mathrm{EtOH}$, then $15 \% \mathrm{HCl}(0.91 \mathrm{~mL})$ was added to this solution and the mixture was cooled to $5{ }^{\circ} \mathrm{C} . \mathrm{NaNO}_{2}(0.4 \mathrm{~g}, 5.7 \mathrm{mmol})$ and 4-hydroxy-2-oxo-1,2-dihydroquinoline-6-carboxylic acid (1.0 g, $5.7 \mathrm{mmol})$ was added slowly under the temperature of $5{ }^{\circ} \mathrm{C}$ and $\mathrm{pH}<7(15 \% \mathrm{HCl})$. The resulting mixture was left in ice overnight. The precipitated solid was then filtered and crystallized from $\mathrm{Et}_{2} \mathrm{O} / \mathrm{EtOH}$. A reddish crystalline compound

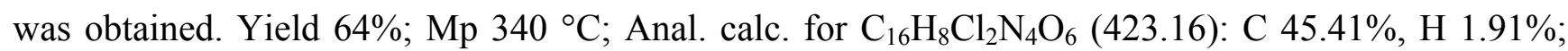
found: C 45.26\%, H 2.24\%; HPLC purity 96.39\%; UV (nm), $\lambda_{\max } / \log \varepsilon: 271.4 / 3.61$; IR $\left(\mathrm{cm}^{-1}\right): 3616$, $1180(\mathrm{OH}), 3030\left(\mathrm{CH}_{\text {arom }}\right), 2950,1680$ (acid), 1670 (lactam), $1655(\mathrm{C}=\mathrm{O}), 1630\left(\mathrm{C}=\mathrm{C}_{\text {cycle }}\right), 1614$ $(\mathrm{N}=\mathrm{N}), 1598(\mathrm{Ph}), 1543\left(\mathrm{NO}_{2}\right), 1520(\mathrm{NH}) ;{ }^{1} \mathrm{H}-\mathrm{NMR}\left(\mathrm{DMSO}-\mathrm{d}_{6}\right) \delta: 5.70(\mathrm{~s}, 1 \mathrm{H}), 7.10-7.60(\mathrm{~m}, 3 \mathrm{H})$, $11.10(\mathrm{~s}, 1 \mathrm{H}), 11.30(\mathrm{~s}, 1 \mathrm{H})$.

Ethyl 4-hydroxy-2-oxo-1,2-dihydroquinoline-3-carboxylate (9). Aniline (0.46 mL, $0.005 \mathrm{~mol})$ and triethyl methanetricarboxylate $(2.12 \mathrm{~mL}, 0.01 \mathrm{~mol})$ were heated in microwave reactor for $8 \mathrm{~min}$ at $60 \%$ power level. The mixture was then cooled to room temperature and $7 \mathrm{~mL}$ of $\mathrm{Et}_{2} \mathrm{O}$ was added. The crude product was crystallized from $\mathrm{MeOH}$. A white crystalline compound was obtained. Yield 50\%; Mp 116-120 ${ }^{\circ} \mathrm{C}$; Anal. calc. for $\mathrm{C}_{12} \mathrm{H}_{11} \mathrm{NO}_{4}$ (233.22): C 61.80\%, $\mathrm{H} 4.75 \%$; found: $\mathrm{C} 61.65 \%, \mathrm{H} 4.39 \%$; HPLC purity 95.01\%; UV (nm), $\lambda_{\max } / \log \varepsilon: 244.2 / 3.59$; IR $\left(\mathrm{cm}^{-1}\right): 3620,1180(\mathrm{OH}), 2958\left(\mathrm{CH}_{3}\right), 2925$ $\left(\mathrm{CH}_{2}\right), 1680$ (lactam), $1638(\mathrm{C}=\mathrm{O}), 1630\left(\mathrm{C}=\mathrm{C}_{\text {cycle }}\right), 1598(\mathrm{Ph}), 1520(\mathrm{NH}), 1191\left(\mathrm{C}=\mathrm{O}_{\text {ester }}\right) ;{ }^{1} \mathrm{H}-\mathrm{NMR}$ $\left(\mathrm{DMSO}_{6}\right) \delta: 1.19(\mathrm{t}, 3 \mathrm{H}), 4.17(\mathrm{q}, 2 \mathrm{H}), 4.70(\mathrm{~s}, 1 \mathrm{H}), 7.09(\mathrm{t}, 2 \mathrm{H}), 7.32(\mathrm{t}, 1 \mathrm{H}), 7.52(\mathrm{~d}, \mathrm{~J}=8.5 \mathrm{~Hz}$, $1 \mathrm{H}), 10.30(\mathrm{t}, 1 \mathrm{H})$.

4-Hydroxy-2-oxo-1,2-dihydroquinoline-3-carboxylic acid (10). The product was obtained according to the described procedure [34,35] as a white crystalline compound. Yield 99\%; Mp $225{ }^{\circ} \mathrm{C}$; HPLC purity 99.51\%; UV (nm), $\lambda_{\max } / \log \varepsilon: 250.1 / 3.52 ; \mathrm{IR}\left(\mathrm{cm}^{-1}\right): 3621,1182(\mathrm{OH}), 2965,1670$ (acid), 1679 (lactam), $1646(\mathrm{C}=\mathrm{O}), 1629\left(\mathrm{C}=\mathrm{C}_{\text {cycle }}\right), 1599(\mathrm{Ph}), 1525(\mathrm{NH})$. 
3-(4-Carboxyphenylcarbamoyl)-4-hydroxy-2-oxo-1,2-dihydroquinoline-6-carboxylic acid (11). 4-Aminobenzoic acid $(0.7 \mathrm{~g}, 0.005 \mathrm{~mol})$ was mixed with triethyl methanetricarboxylate $(2.12 \mathrm{~mL}$, $0.01 \mathrm{~mol}$ ) and heated in microwave reactor at $50 \%$ of power during $15 \mathrm{~min}$ and $3 \mathrm{~min}$ at $90 \%$. The temperature reached $231{ }^{\circ} \mathrm{C}$ during heating. $\mathrm{Et}_{2} \mathrm{O}$ was added to the cooled mixture and the precipitate was washed with hot $\left(55^{\circ} \mathrm{C}\right) \mathrm{MeOH}$ to obtain the pure product as a yellow crystalline compound. Yield 62\%; Mp 340-350 ${ }^{\circ} \mathrm{C}$; Anal. calc. for $\mathrm{C}_{18} \mathrm{H}_{12} \mathrm{~N}_{2} \mathrm{O}_{7}$ (368.29): C 58.70\%, H 3.28\%; found: C $58.09 \%$, H 3.54\%; HPLC purity 97.52\%; UV (nm), $\lambda_{\max } / \log \varepsilon: 251.3 / 3.53$; IR $\left(\mathrm{cm}^{-1}\right): 3621,1180$ (OH), 3034 ( $\left.\mathrm{CH}_{\text {arom}}\right), 2970,1689$ (acid), 1680 (lactam), $1642(\mathrm{C}=\mathrm{O}), 1635\left(\mathrm{C}=\mathrm{C}_{\text {cycle }}\right), 1630$ (amide), $1599(\mathrm{Ph}), 1520(\mathrm{NH}) ;{ }^{1} \mathrm{H}-\mathrm{NMR}\left(\mathrm{DMSO}_{6}\right) \delta: 7.41$ (d, $\left.J=8.5 \mathrm{~Hz}, 1 \mathrm{H}\right), 7.70$ (d, J=9.1 Hz, 2H), 7.90 (d, J=9.1 Hz, 2H), 8.15 (d, J=8.5 Hz, 1H), 8.50 (s, 1H), 12.40 (s, 1H), 12.95 (s, 1H), 16 (s, 1H).

3-(4-Carboxy-3-hydroxyphenylcarbamoyl)-4-hydroxy-2-oxo-1,2-dihydroquinoline-6-carboxylic acid (12). 4-Aminosalicylic acid $(0.7 \mathrm{~g}, 0.005 \mathrm{~mol})$ was mixed with triethyl methanetricarboxylate $(2.12$ $\mathrm{mL}, \quad 0.01 \mathrm{~mol})$ and heated in microwave reactor at $50 \%$ of power for $15 \mathrm{~min}$ and $3 \mathrm{~min}$ at $90 \%$. The temperature reached $230{ }^{\circ} \mathrm{C}$ during heating. $\mathrm{Et}_{2} \mathrm{O}$ was added to the cooled mixture and the precipitate was washed with hot $\left(55^{\circ} \mathrm{C}\right) \mathrm{MeOH}$ to obtain the pure product as a yellow crystalline compound. Yield $20 \%$; Mp $350{ }^{\circ} \mathrm{C}$; Anal. calc. for $\mathrm{C}_{18} \mathrm{H}_{12} \mathrm{~N}_{2} \mathrm{O}_{9}$ (400.29): C 54.01\%, H 3.02\%; found: C 54.05\%, H 9.94\%; HPLC purity 96.42\%; UV (nm), $\lambda_{\max } / \log \varepsilon: 256.0 / 3.53$; IR $\left(\mathrm{cm}^{-1}\right)$ : 3620, $1179(\mathrm{OH}), 3035\left(\mathrm{CH}_{\text {arom }}\right), 2972,1688$ (acid), 1680 (lactam), $1640(\mathrm{C}=\mathrm{O}), 1633$ $\left(\mathrm{C}=\mathrm{C}_{\text {cycle }}\right), 1632($ amide $), 1600(\mathrm{Ph}), 1521(\mathrm{NH}), 1329,1199\left(\mathrm{OH}_{\text {phenol }}\right) ;{ }^{1} \mathrm{H}-\mathrm{NMR}\left(\mathrm{DMSO}-d_{6}\right) \delta: 7.43$ (d, J=8.5 Hz, 2H), 7.7 (s, 1H), 7.9 (m, 3H), 10.43 (s, 1H), 10.47 (s, 1H), 12.7 (s, 1H) 16.0 (s, 1H).

\subsection{Lipophilicity HPLC determination (capacity factor $k$ / calculated log $k$ )}

The HPLC separation module Waters Alliance 2695 XE and Waters Photodiode Array Detector 2996 (Waters Corp., Milford, MA, U.S.A.) were used. A Symmetry ${ }^{\circledR} \mathrm{C}_{18} 5 \mu \mathrm{m}, 4.6 \times 250 \mathrm{~mm}$, Part No. WAT054275, (Waters Corp., Milford, MA, U.S.A.) chromatographic column was used. The HPLC separation process was monitored by Millennium $32^{\circledR}$ Chromatography Manager Software, Waters 2004 (Waters Corp., Milford, MA, U.S.A.). The mixture of $\mathrm{MeOH}$ p.a. (55.0\%) and $\mathrm{H}_{2} \mathrm{O}-$ HPLC - Mili-Q Grade (45.0\%) was used as a mobile phase. The total flow of the column was 0.9 $\mathrm{mL} / \mathrm{min}$, injection $30 \mu \mathrm{L}$, column temperature $30{ }^{\circ} \mathrm{C}$ and sample temperature $10{ }^{\circ} \mathrm{C}$. The detection wavelength $210 \mathrm{~nm}$ was chosen. The KI methanolic solution was used for the dead time $\left(\mathrm{T}_{\mathrm{D}}\right)$ determination. Retention times $\left(t_{R}\right)$ were measured in minutes. The capacity factors $k$ were calculated using the Millennium $32^{\circledR}$ Chromatography Manager Software according to formula $k=\left(t_{R}-t_{D}\right) / t_{D}$, where $t_{R}$ is the retention time of the solute, whereas $t_{D}$ denotes the dead time obtained via an unretained analyte. Log $k$, calculated from the capacity factor $k$, is used as the lipophilicity index converted to $\log P$ scale. The $\log k$ values of the individual compounds are shown in Table 1.

\subsection{Lipophilicity calculations}

$\log P$, i.e. the logarithm of the partition coefficient for $n$-octanol/water, was calculated using the programs CS ChemOffice Ultra ver. 9.0 (CambridgeSoft, Cambridge, MA, U.S.A.) and ACD/LogP ver. 1.0 (Advanced Chemistry Development Inc., Toronto, Canada). Clog $P$ values (the logarithm of 
$n$-octanol/water partition coefficient based on established chemical interactions) were generated by means of CS ChemOffice Ultra ver. 9.0 (CambridgeSoft, Cambridge, MA, U.S.A.) software. The results are shown in Table 1.

\subsection{Study of inhibition of oxygen evolution rate (OER) in spinach chloroplasts}

Chloroplasts were prepared from spinach (Spinacia oleracea L.) according to Masarovicova and Kralova [36]. The inhibition of photosynthetic electron transport (PET) in spinach chloroplasts was determined spectrophotometrically (Genesys 6, Thermo Scientific, U.S.A.) using an artificial electron acceptor 2,6-dichlorophenol-indophenol (DCPIP) according to Kralova et al. [37] and the rate of photosynthetic electron transport was monitored as a photoreduction of DCPIP. The measurements were carried out in phosphate buffer $(0.02 \mathrm{~mol} / \mathrm{L}, \mathrm{pH} 7.2)$ containing sucrose $(0.4 \mathrm{~mol} / \mathrm{L}), \mathrm{MgCl}_{2}$ $(0.005 \mathrm{~mol} / \mathrm{L})$ and $\mathrm{NaCl}(0.015 \mathrm{~mol} / \mathrm{L})$. The chlorophyll content was $30 \mathrm{mg} / \mathrm{L}$ in these experiments and the samples were irradiated $\left(\sim 100 \mathrm{~W} / \mathrm{m}^{2}\right)$ from $10 \mathrm{~cm}$ distance with a halogen lamp $(250 \mathrm{~W})$ using a $4 \mathrm{~cm}$ water filter to prevent warming of the samples (suspension temperature $22{ }^{\circ} \mathrm{C}$ ). The studied compounds were dissolved in DMSO due to their limited water solubility. The applied DMSO concentration (up to 4\%) did not affect the photochemical activity in spinach chloroplasts. The inhibitory efficiency of the studied compounds was expressed by $\mathrm{IC}_{50}$ values, i.e. by molar concentration of the compounds causing $50 \%$ decrease in the oxygen evolution rate relative to the untreated control. The comparable $\mathrm{IC}_{50}$ value for a selective herbicide 3-(3,4-dichlorophenyl)-1,1dimethylurea, DCMU (Diurone ${ }^{\circledR}$ ) was about $1.9 \mu \mathrm{mol} / \mathrm{L}$ [38]. The results are summarized in Table 2.

\subsection{In vitro antifungal susceptibility testing}

The broth microdilution test [27,39] was used for the assessment of in vitro antifungal activity of the synthesized compounds against Candida albicans ATCC 44859 (CA), Candida tropicalis 156 (CT), Candida krusei ATCC 6258 (CK), Candida glabrata 20/I (CG), Trichosporon beigelii 1188 (TB), Aspergillus fumigatus 231 (AF), Absidia corymbifera 272 (AC), and Trichophyton mentagrophytes 445 (TM). Fluconazole (FLU) was used as the standard of a clinically used antimycotic drug. The procedure was performed with twofold dilution of the compounds in RPMI 1640 (Sevapharma a.s., Prague, Czech Republic) buffered to pH 7.0 with 0.165 mol of 3-morpholinopropane-1-sulfonic acid (MOPS, Sigma, Germany). The final concentrations of the compounds ranged from 500 to $0.975 \mu \mathrm{mol} / 1$. Drug-free controls were included. The MIC was defined as an $80 \%$ or greater $\left(\mathrm{IC}_{80}\right)$ reduction of growth in comparison with the control. The values of MICs were determined after 24 and $48 \mathrm{~h}$ of static incubation at $35^{\circ} \mathrm{C}$. For T. mentagrophytes, the final MICs were determined after 72 and $120 \mathrm{~h}$ of incubation. The results are summarized in Table 2.

\section{Acknowledgements}

This study was supported by the Polish Ministry of Science N405 178735, by the Ministry of Education of the Czech Republic MSM 6215712403, by the Slovak Scientific Grant Agency VEGA 1/0089/03, and by the Irish Department of Education and Science TSR Strand1-06/CR08. 


\section{References}

1. Roth, H.J.; Fenner, H. Arzneistoffe, $3^{\text {rd }}$ Ed.; Deutscher Apotheker Verlag: Stuttgart, Germany, 2000; pp. 51-114.

2. Polanski, J.; Niedbala, H.; Musiol, R.; Podeszwa, B.; Tabak, D.; Palka, A.; Mencel, A.; Finster, J.; Mouscadet, J.F.; Le Bret, M. 5-Hydroxy-8-nitro-6-quinaldic Acid as a Novel Molecular Scaffold for HIV-1 Integrase Inhibitors. Lett. Drugs Des. Disc. 2006, 3, 175-178.

3. Polanski, J.; Niedbala, H.; Musiol, R.; Podeszwa, B.; Tabak, D.; Palka, A.; Mencel, A.; Mouscadet, J.F.; Le Bret, M. Fragment Based Approach for the Investigation of HIV-1 Integrase Inhibition. Lett. Drugs Des. Disc. 2007, 4, 99-105.

4. Vargas, L.Y.; Castelli, M.V.; Kouznetsov, V.V.; Urbina, J.M.; Lopez, S.N.; Sortino, M.; Enriz, R.D.; Ribas, J.C.; Zacchino, S. In vitro Antifungal Activity of New Series of Homoallylamines and Related Compounds with Inhibitory Properties of the Synthesis of Fungal Cell Wall Polymers. Bioorg. Med. Chem. 2003, 11, 1531-1550.

5. Jampilek, J.; Dolezal, M.; Kunes, J.; Buchta, V. Quinaldine derivatives preparation and their antifungal activity. ECSOC-8 2004, c005, http://www.lugo.usc.es/\%7Eqoseijas/ECSOC-8/ BOCNP/005/index.htm.

6. Jampilek, J.; Dolezal, M.; Kunes, J.; Buchta, V.; Kralova, K. Quinaldine Derivatives: Preparation and Biological Activity. Med. Chem. 2005, 1, 591-599.

7. Musiol, R.; Jampilek, J.; Buchta, V.; Niedbala, H.; Podeszwa, B.; Palka, A.; Majerz-Maniecka, K.; Oleksyn, B.; Polanski, J. Antifungal Properties of New Series of Quinoline Derivatives. Bioorg. Med. Chem. 2006, 14, 3592-3598.

8. Musiol, R.; Jampilek, J.; Kralova, K.; Podeszwa, B.; Finster, J.; Niedbala, H.; Palka, A.; Polanski, J. New quinoline derivatives possessing herbicidal activity. ECSOC-9 2005, c005, http://www.usc.es/congresos/ecsoc/9/BOCNP/c005/index.htm.

9. Musiol, R.; Jampilek, J.; Kralova, K.; Tabak, D.; Podeszwa, B.; Finster, J.; Polanski, J. Substituted amides of quinoline derivatives: preparation and their photosynthesis-inhibiting activity. ECSOC-10 2006, c007, http://www.usc.es/congresos/ecsoc/10/ECSOC10.htm.

10. Musiol, R.; Jampilek, J.; Kralova, K.; Richardson, D.R.; Kalinowski, D.; Podeszwa, B.; Finster, J.; Niedbala, H.; Palka, A.; Polanski, J. Investigating Biological Activity Spectrum for Novel Quinoline Analogues. Bioorg. Med. Chem. 2007, 15, 1280-1288.

11. Musiol, R.; Jampilek, J.; Kralova, K.; Tabak, D.; Finster, J.; Podeszwa, B.; Kozik, V.; Dohnal, J.; Polanski, J. Preparation and Herbicidal Activities of Substituted Amides of Quinoline Derivatives. ECSOC-11 2007, a011, http://www.usc.es/congresos/ecsoc/11/hall_aGOS/a011/index.htm.

12. Musiol, R.; Tabak, D.; Niedbala, H.; Podeszwa, B.; Jampilek, J.; Kralova, K.; Dohnal, J.; Finster, J.; Mencel, A.; Polanski, J. Investigating Biological Activity Spectrum for Novel Quinoline Analogues 2: Hydroxyquinolinecarboxamides with Photosynthesis Inhibiting Activity. Bioorg. Med. Chem. 2008, 16, 4490-4499.

13. Musiol, R.; Jampilek, J.; Kralova, K.; Finster, J.; Tabak, D.; Niedbala, H.; Csollei, J.; Dohnal, J.; Polanski, J. Ring-substituted 4-hydroxy-1H-quinolin-2-ones: Preparation and Their Photosynthesis-inhibiting Activity. ECSOC-12 2008, c0012, http://www.usc.es/congresos/ecsoc/ 12/ECSOC12.htm. 
14. Podeszwa, B.; Niedbala, H.; Polanski, J.; Musiol, R.; Tabak, D.; Finster, J.; Serafin, K.; Wietrzyk, J.; Boryczka, S.; Mol, W.; Jampilek, J.; Dohnal, J.; Kalinowski, D.; Richardson, D.R. Investigating the Antiproliferative Activity of Quinoline-5,8-dione Analogues on Tumour Cell Lines. Bioorg. Med. Chem. Lett. 2007, 17, 6138-6141.

15. Reifler, M.J.; Szalai, V.A.; Peterson, C.N.; Brudvig, G.W. Effects of Tail-like Substituents on the Binding of Competitive Inhibitors to the $\mathrm{Q}_{\mathrm{B}}$ Site of Photosystem II. J. Mol. Recognit. 2001, 14, 157-165.

16. Moreland D.E. Research on Biochemistry of Herbicides - an Historical Overview. Z. Naturforsch. C-A J. Biosci. 1993, 48, 121-131.

17. Zakarya, D.; Larfaoui, E.M.; Boulaamail, A.; Tollabi, M.; Lakhlifi, T. QSARs for a Series of Inhibitory Anilides. Chemosphere 1998, 36, 2809-2818.

18. Kralova, K.; Sersen, F.; Kubicova, L.; Waisser, K. Inhibitory Effects of Substituted Benzanilides on Photosynthetic Electron Transport in Spinach Chloroplasts. Chem. Pap. 1999, 53, 328-331.

19. Dolezal, M.; Miletin, M.; Kunes, J.; Kralova, K. Synthesis and Biological Evaluation of Some Amides of Pyrazine-2-carboxylic acids Molecules 2002, 7, 363-373.

20. Dolezal, M.; Palek, L.; Vinsova, J.; Buchta, V.; Jampilek, J.; Kralova, K. Substituted Pyrazinecarboxamides: Synthesis And Biological Evaluation. Molecules 2006, 11, 242-256.

21. Dolezal, M.; Cmedlova, P.; Palek, L.; Vinsova, J.; Kunes, J.; Buchta, V.; Jampilek, J.; Kralova, K. Synthesis and Antimycobacterial Evaluation of Substituted Pyrazinecarboxamides. Eur. J. Med. Chem. 2008, 43, 1105-1113.

22. Polak, A. The past, Present and Future of Antimycotic Combination Therapy. Mycoses 1999, 42, 355-370.

23. Fostel, J.M.; Lartey, P.A. Emerging Novel Antifungal Agents. Drug Discov. Today 2000, 5, 25-32.

24. http://www.doctorfungus.org/, accessed on January 30, 2009.

25. Gershon, H; Gershon, M; Clarke, D.D. Synergistic Mixtures of Fungitoxic Monochloro- and Dichloro-8-quinolinols against Five Fungi. Mycopathologia 2004, 158, 131-135.

26. Dardari, Z.; Lemrani, M.; Bahloul, A.; Sebban, A.; Hassar, M.; Kitane, S.; Berrada, M.; Boudouma, M. Antileishmanial Activity of a New 8-Hydroxyquinoline Derivative Designed 7-[5'-(3'-phenylisoxazolino)methyl]-8-hydroxyquinoline: preliminary study. Farmaco 2004, 59, 195-199.

27. Sheehan, D.J.; Espinel-Ingroff, A.; Steele, M.; Webb, C.D. Antifungal Susceptibility Testing of Yeasts: a Brief Overview. Clin. Infect. Dis. 1993, 17, 494-500.

28. Dolezal, M.; Jampilek, J.; Osicka, Z.; Kunes, J.; Buchta, V.; Vichova, P. Substituted 5-aroylpyrazine-2-carboxylic Acid Derivatives: Synthesis and Biological Activity. Farmaco 2003, 58, 1105-1111.

29. Collins, J.F.; Donnelly, W.J.; Grundon, M.F.; James, K.J. Biosynthesis of Aromatic Isoprenoids. Part I. The role of 3-Prenylquinolines and of Platydesmine in the Biosnthesis of the Furuquinoline Alkaloid, Dictamnine. J. Chem. Soc., Perkin Trans. 1974, 1, 2177-2181.

30. Buckle, D.R.; Cantello, B.C.C.; Smith, H.; Spicer, B.A. 4-Hydroxy-3-nitro-2-quinolones and Related Compounds as Inhibitors of Allergic Reactions. J. Med. Chem. 1975, 18, 726-732. 
31. Ziegler, E.; Wolf, R.; Kappe, T. Synthesen von Heterocyclen, 66. Mitt.: Eine Einfache Synthese des 4-Hydroxycarbostyrils und seiner Derivate. Monatsh. Chem. 1965, 96, 418-422.

32. Dolle, V.; Fan, E.; Nguyen, C.H.; Aubertin, A.M.; Kirn, A.; Andreola, M.L.; Jamieson, G.; Tarrago-Litvak, L.; Bisagni, E. A New Series of Pyridinone Derivatives as Potent nonNucleoside Human Immunodeficiency Virus Type 1 Specific Reverse Transcriptase Inhibitors. J. Med. Chem. 1995, 38, 4679-4686.

33. Ukrainets, I.V.; Taran, S.G.; Sidorenko, L.V.; Gorokhova, O.V.; Ogirenko, A.A.; Turov, A.V.; Filimonova, N.I. 4-Hydroxy-2-quinolones. 3-Amino-1-R-2-oxo-4-hydroxyquinolines and Their Acyl Derivatives. Chem. Heterocycl.Compd. 1996, 32, 960-970.

34. Ukrainets, I.V.; Gorokhova, O.V.; Sidorenko, L.V. 4-Hydroxyquinol-2-ones. 85. Synthesis of 2-Chloro-4-hydroxyquinoline-3-carboxylic Acid Ethyl Ester. Chem. Heterocycl. Compd. 2005, 41, 1019-1021.

35. Detsi, A.; Bardakos, V.; Markopoulos, J.; Igglessi-Markopoulou, O. Reactions of 2-Methyl-3,1benzoxazin-4-one with Active Methylene Compounds: a New Route to 3-Substituted 4-Hydroxyquinolin-2(1H)-ones. J. Chem. Soc., Perkin Trans. 1 1996, 24, 2909-2913.

36. Masarovicova, E.; Kralova, K. Approaches to Measuring Plant Photosynthesis Activity. In Handbook of Photosynthesis $2^{\text {nd }}$ Ed.; Pessarakli, M., Ed.; Taylor \& Francis Group: Boca Raton, London-New York-Singapore, 2005; pp. 617-656.

37. Kralova, K.; Sersen, F.; Sidoova, E. Photosynthesis Inhibition Produced by 2-Alkylthio-6-Rbenzothiazoles Chem. Pap. 1992, 46, 348-350.

38. Fedke, C. Biochemistry and Physiology of Herbicide Action. Springer Verlag: Berlin-HeidelbergNew York, USA, 1982.

39. National Committee for Clinical Laboratory standards. Reference Method for Broth Dilution Antifungal Susceptibility Testing of Yeast: Approved Standard, NCCLS document M27-A; NCCLS: Villanova, PA, USA, 1997.

Sample Availability: Samples of the compounds are available from the authors.

(C) 2009 by the authors; licensee Molecular Diversity Preservation International, Basel, Switzerland. This article is an open-access article distributed under the terms and conditions of the Creative Commons Attribution license (http://creativecommons.org/licenses/by/3.0/). 